SUPPORTING INFORMATION FOR:

\title{
Synthesis and Characterization of the Amphoteric Amino Acid Bifunctional Mesoporous Silica
}

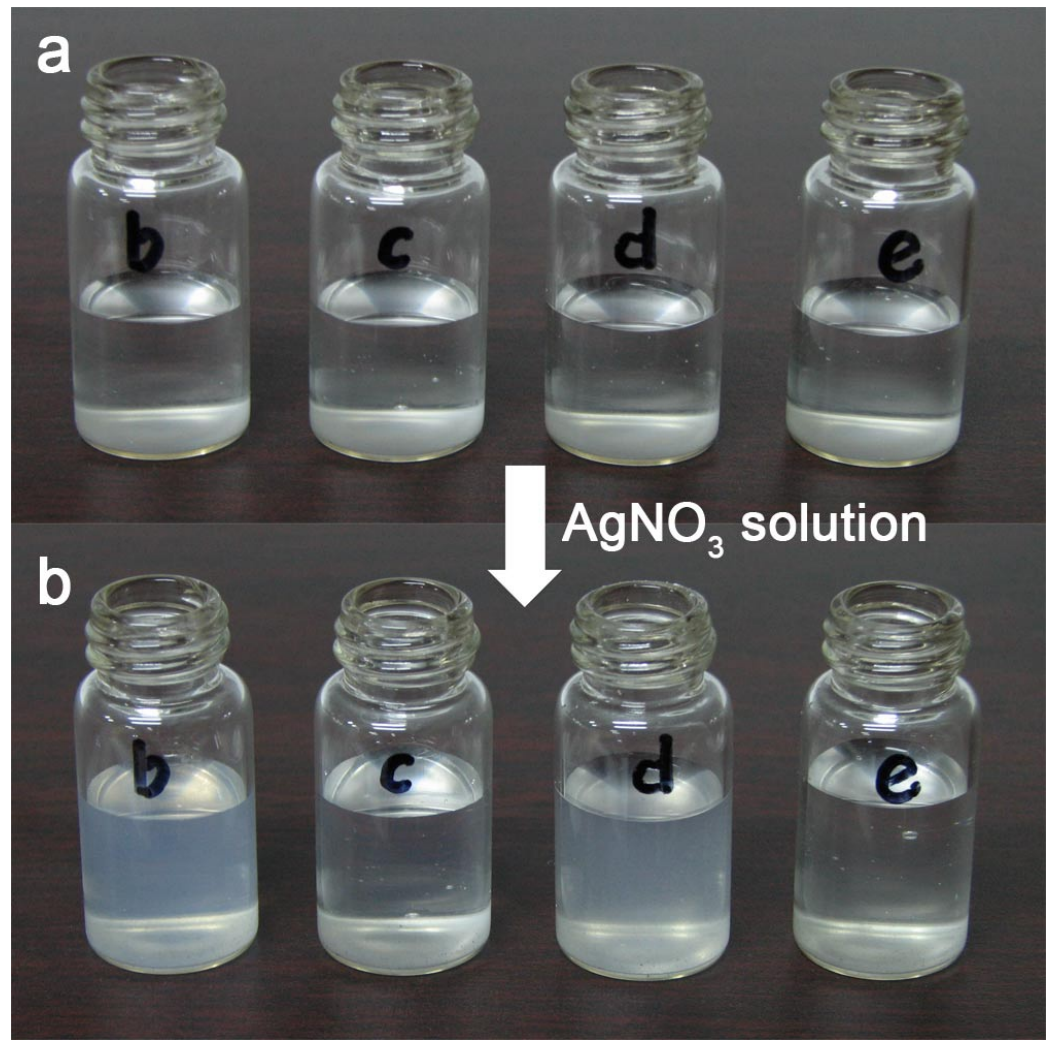

Figure S1. The pictures of aqueous solutions of different samples (shown in Figure 5) before (a) and after (b) addition of silver nitrate. 


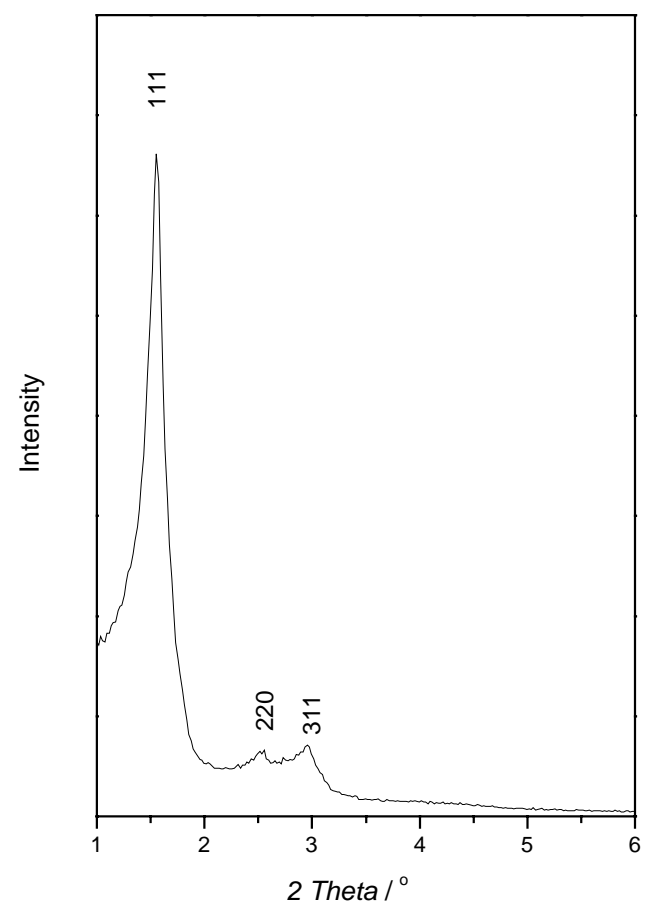

Figure S2. Powder XRD pattern of the DCC-promoted amide containing material obtained by coupling reaction of the carboxylic acid and the protonated ammonium groups on the surface of the mesopores 